To be published in Multiscale and Multiphysics Processes in

Geomechanics (results of a workshop at Stanford University, 23-25

June, 2010), Springer Series in Geomechanics and Geoengineering,

edited by Ronaldo I. Borja, ISBN 978-3-642-19629-4, 2011.

\title{
EARTHQUAKE SEQUENCE CALCULATIONS WITH DYNAMIC WEAKENING MECHANISMS
}

\author{
Hiroyuki Noda ${ }^{1, *}$, Nadia Lapusta ${ }^{1,2}$, and James R. Rice ${ }^{3}$ \\ ${ }^{1}$ Division of Geological and Planetary Sciences \\ California Institute of Technology \\ 1200 E. California Blvd. Pasadena CA 91125 \\ e-mail: hnoda@caltech.edu \\ ${ }^{2}$ Division of Engineering and Applied Science \\ California Institute of Technology \\ 1200 E. California Blvd. Pasadena CA 91125 \\ e-mail: lapusta@its.caltech.edu,web page: http://www.gps.caltech.edu/ lapusta/ \\ ${ }^{3}$ Department of Earth and Planetary Sciences and School of Engineering and Applied Sciences \\ Harvard University \\ 29 Oxford Street, Cambridge, MA 02138 \\ e-mail: rice@seas.harvard.edu, web page: http://esag.harvard.edu/rice/
}

Keywords: Sequence of Earthquakes, Friction, Strong rate-weakening, Frictional heating

\section{INTRODUCTION}

Mature faults sustain low shear stress interseismically and during coseismic slip, as indicated by measurements of near-fault stress orientations (e.g., [1]) and observations of low heat flux [2]. At the same time, earthquake stress drops are typically between 1 and $10 \mathrm{MPa}$ (e.g., [3]) which is much smaller than an expected value of shear strength at seismogenic depths $(\sim 100 \mathrm{MPa})$. These observations suggest that most fault points have low shear stress before large earthquakes, slip mainly at even lower shear stresses, and lock with the final stress only modestly lower than the initial value. [4], [5], and [6] demonstrated that even if a fault is strong at low slip rates, a dynamic rupture can propagate on a low-stressed fault (shear stress / normal stress $\sim 0.3$ or less) if the strength of a fault dramatically decreases coseismically, and discussed the operation of a fault at a low long-term shear stress.

Our aim is to elucidate effects of coseismically activated weakening mechanisms on the long-term fault behavior by conducting earthquake sequence simulations, following [4]. We have expanded the methodology that allows to simulate long slip histories while accounting for inertial effects during earthquakes $[7,8]$ to include strong dynamic weakening due to flash heating $(\mathrm{FH})$ of microscopic contacts and thermal pressurization (TP) of pore fluids. Improvements over [4] include a more stable numerical algorithm and code parallelization that allows to explore more realistic parameter regimes.

R.I. Borja (Ed.): Multiscal and Multiphysics Processes in Geomechanics, SSGG, pp 149-152. 


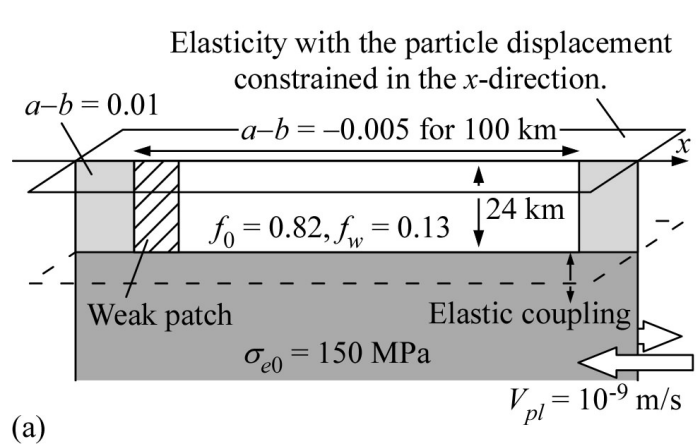

(a)

(b)

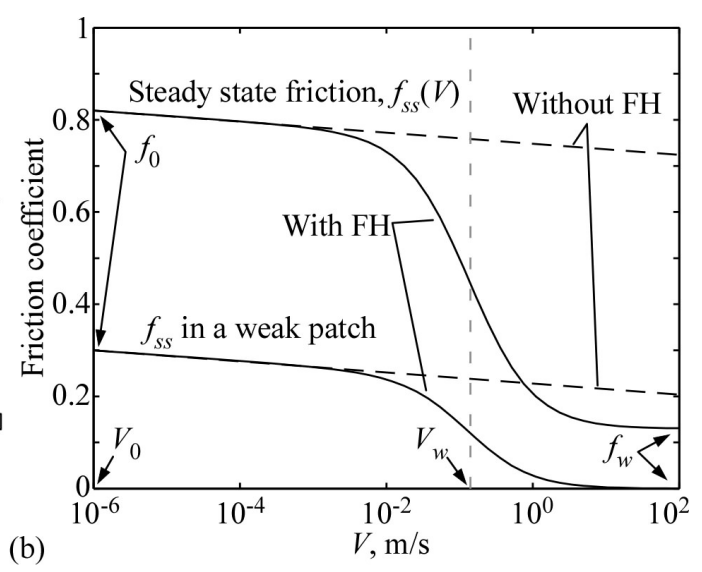

Figure 1. (a) A schematic diagram of the crustal-plane model. (b) Steady-state friction coefficient, $f_{s s}(V)$, in the law with strong rate weakening due to $\mathrm{FH}$.

\section{THERMAL WEAKENING MECHANISMS}

Recent experimental studies (e.g. [9]) revealed that friction coefficients of rocks dramatically decrease at high slip rates $(>0.1 \mathrm{~m} / \mathrm{s})$. Such behavior can be explained by highly concentrated heat production in narrow shear zones and the resulting effects [10].

One such effect is temperature rise at microscopic frictional contacts $(\mathrm{FH})$ which predicts $f$ $\sim 1 / V+$ const. at $V$ larger than about $0.1 \mathrm{~m} / \mathrm{s}$, where $f$ is the friction coefficient and $V$ is the slip rate. We add this effect to the Dieterich-Ruina rate-and-state friction law (Figure 1b):

$$
\begin{aligned}
& \tau=\sigma_{e} f(V, \theta)=\left(\sigma_{n}-p(y=0)\right) a \sinh ^{-1}\left\{\frac{V}{2 V_{0}} \exp \left(\frac{f_{0}+b \ln \theta}{a}\right)\right\} \\
& f_{s s}(V)=\frac{f\left(V, V_{0} /|V|\right)-f_{w} V /|V|}{1+|V| / V_{w}}+f_{w} \frac{V}{|V|} \equiv f\left(V, \theta_{s s}(V)\right), \quad \dot{\theta}=\frac{|V|}{L}\left(\theta_{s s}(V)-\theta\right)
\end{aligned}
$$

where $\tau$ is the shear stress, $\sigma_{e}$ and $\sigma_{n}$ are the effective and total normal stresses, $p$ is pore pressure, $y$ is the coordinate normal to the fault, $\theta$ is a state variable, $a$ and $b$ are rate and state parameters, $L$ is the state evolution distance, $V_{0}$ and $f_{0}$ are the reference slip rate and friction coefficient, $V_{w}$ is the slip rate at which $\mathrm{FH}$ becomes efficient, and $f_{w}$ is the residual friction coefficient. Note that the aging effect in this law is important to simulate earthquake sequences including interseismic periods.

\section{EARTHQUAKE SEQUENCES IN 2D CRUSTAL PLANE MODELS}

In our simulation example, a $24-\mathrm{km}$ deep elastic plate (depth-averaged to a crustal plane) is loaded by steady-state slip at $10^{-9} \mathrm{~m} / \mathrm{s}$ at the deeper fault extension (Figure 1a). The depthaveraged elastodynamic equation for the strike-parallel displacement $u(x, y, t)$ incorporates the plate loading $V_{p l}$ and is given as eq. (A1) in [8]. On the fault, slip rate and shear stress are given by $V=2\left(\partial u\left(x, y=0^{+}, t\right) / \partial t\right)$ and $\tau=\mu \times\left(\partial u\left(x, y=0^{+}, t\right) / \partial y\right)$, respectively. We examine the behavior of a $100-\mathrm{km}$ rate-weakening region surrounded by stable rate-strengthening areas. 
The region has a $10-\mathrm{km}$ weak region of low $f_{0}$ at one end which produces frequent nucleation of seismic ruptures. $f_{s s}(V)$ in the seismogenic region is shown in Figure $1 \mathrm{~b}$.

Although the strength at each point on the fault at low slip rates is high $\left(\sigma_{e} f_{0} \sim 100 \mathrm{MPa}\right)$, averaged shear stress on a fault is low because of low coseismic shear stress and frequent rupture nucleation, consistent with the results of [4], [5], [6]. Long-term shear stress distribution and averaged shear stress in the seismogenic region $(-50 \mathrm{~km}<x<50 \mathrm{~km})$ is shown in Figures 2a and b, respectively, for cases with $L=10 \mathrm{~mm}$.
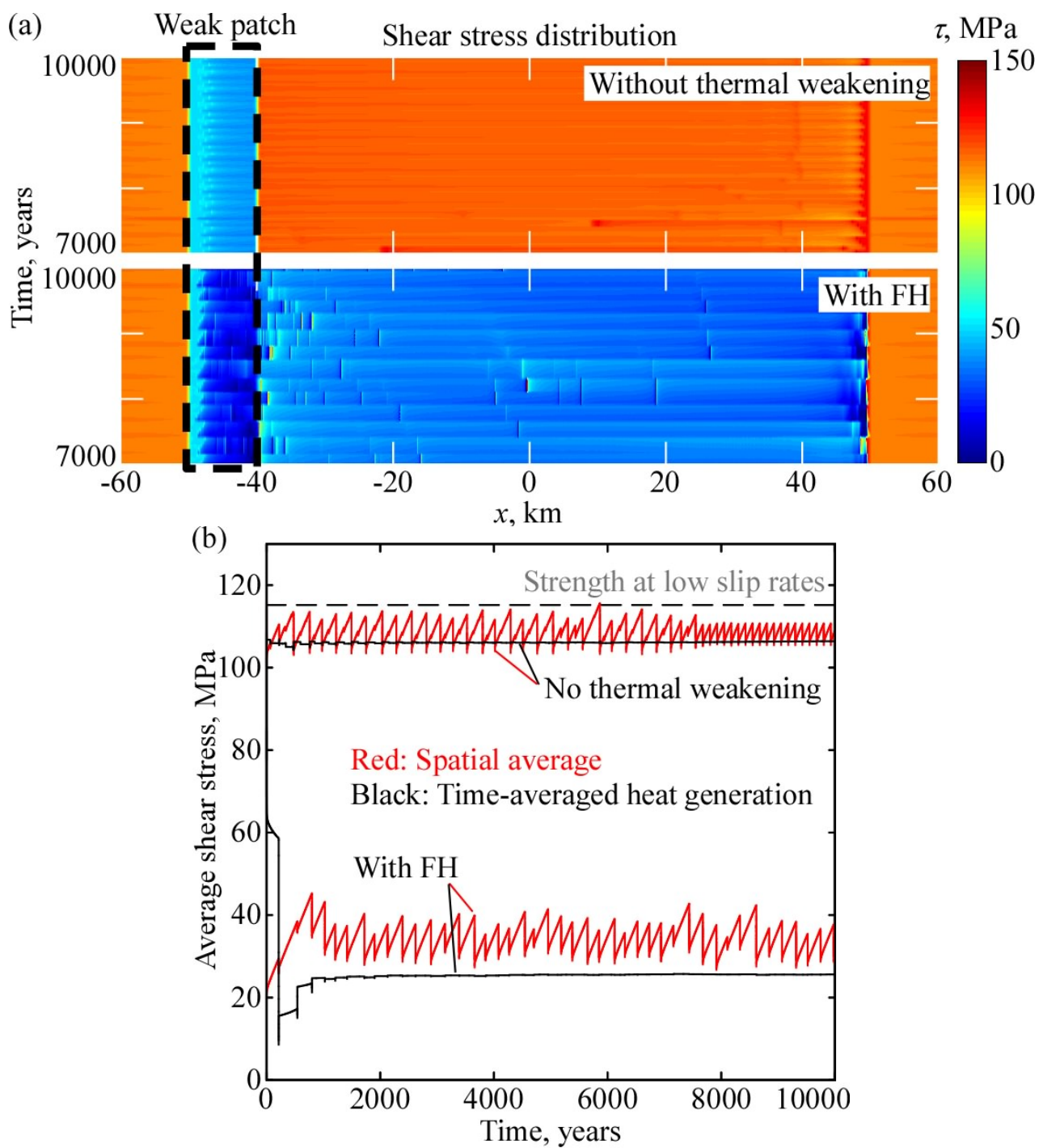

Figure 2. (a) Shear stress distribution between 7000-10000 years from the initiation of calculation without thermal weakening (top) and with FH (bottom). (b) Average shear stress (red) and time-averaged heat generation rate (black) in the seismogenic region $(-50 \mathrm{~km}<x<50 \mathrm{~km})$. Interseismic shear stress and long-term heat generation are significantly reduced by thermal weakening due to flash heating. 


\section{CONCLUSIONS}

Fault models that combine high static strength as shown in the lab, low dynamic strength due to flash heating, and locations for earthquake nucleation result in fault operation under low overall shear stress and with low heat production, as supported by observations. This is demonstrated by our long-term simulations of fault slip that incorporate both tectonically slow loading and inertial effects during seismic events.

\section{REFERENCES}

[1] J. Townend and M. D. Zoback, Regional tectonic stress near the San Andreas fault in central and southern California, Geophys. Res. Lett., 31, L15S11, doi:10.1029/203GL018918 (2004).

[2] A. H. Lachenbruch and J. H. Sass, Heat flow and energetics of the San Andreas fault zone, J. Geophys. Res., $85,6185-6223$ (1980).

[3] H. Kanamori, and D. L. Anderson, Theoretical basis of some empirical relations in seismology, Bull. Seism. Soc. Am., 65(5), 1073-1095 (1975).

[4] N. Lapusta and J. R. Rice, Low-heat and low-stress fault operation in earthquake models of statically strong but dynamically weak faults, EOS Trans. AGU, 84(46), Fall Meet. Suppl., Abstract S51B-02 (2003).

[5] H. Noda, E. M. Dunham, and J. R. Rice, Earthquake ruptures with thermal weakening and the operation of major faults at low overall stress levels, J. Geophys. Res., 114, B07302, doi:10.1029/2008JB006143, 27 pages, (2009).

[6] J. R. Rice, E. M. Dunham, and H. Noda, Thermo- and hydro-mechanical processes along faults during rapid slip, in proceedings of the Batsheva de Rothschild Seminar on Shear Physics at the Meso-scale in Earthquake and Landslide Mechanics, Ein Gedi, Israel, 26-30 January 2009), eds. Y. Hatzor, J. Sulem, and I. Vardoulakis, pp. 3-16, CRC Press, (2009).

[7] N. Lapusta, J. R. Rice, Y. Ben-Zion, and G. Zheng, Elastodynamic analysis for slow tectonic loading with spontaneous rupture episodes on faults with rate- and state-dependent friction, J. Geophys. Res., 105 (B10), 23,765-23,790, doi:10.1029/2000JB900250, (2000).

[8] Y. Kaneko and N. Lapusta, Variability of earthquake nucleation in continuum models of rate - and - state faults and implications for aftershock rates, J. Geophys. Res., 113, B12312, doi:10.1029/2007JB005154, (2008).

[9] N. Beeler, T. E. Tullis, and D. L. Goldsby, Constitutive relationships and physical basis of fault strength due to flash heating, J. Geophys. Res., 113, B01401, doi:10.1029/2007JB004988 (2008).

[10] J. R. Rice, Heating and weakening of faults during earthquake slip, J. Geophys. Res., 111, B05311, doi:10.1029/2005JB004006 (2006).

Summary, to appear at start of published version:
There are multiple lines of evidences that major faults which host
large earthquakes (e.g., San Andreas fault) are operating at much
lower shear stresses than what is predicted by Byerlee's law and
a litho- and hydro-static stress state. Recent lab-experimental
studies suggest that a fault weakens dramatically at coseismic slip
rates. We have taken the experimentally derived dynamic weakening into
account in the earthquake sequence simulations, and have revealed that
the overall stress level at which a fault operates is controlled by
the frictional resistance at coseismic slip rates, not that at low slip
rates near the plate velocity.

